$\ni$ ффективность и переносимость терапии акне с использованием системного изотретиноина

Ю.Н. Перламутров ${ }^{1}$, К.Б. Ольховская ${ }^{1}$, М.М. Кохан², Ю.В. Кениксфест², Ю.Б. Шайбакова², Н.В. Полякова², Е.П. Топычканова2, Я.В. Кащеева², А.В. Самцов³, А.В. Стаценкоㄹ, И.Э. Белоусова ${ }^{3}$, В.Р. Хайрутдинов ${ }^{3}$, С.В. Волкова ${ }^{3}$, А.С. Жуков ${ }^{3}$

${ }^{1}$ ГБОУ ВПО «Московский государственный медико-стоматологический университет им. А.И. Евдокимова» Минздрава России

127473, Москва, ул. Делегатская, д. 20, стр. 1

2 ФГБУ «Уральский научно-исследовательский институт дерматовенерологии и иммунопатологии» Минздрава России 620023 , г. Екатеринбург, ул. Щербакова, д. 8

${ }^{3}$ ФГБВОУ ВПО «Военно-медицинская академия им. С.М. Кирова» МО РФ

194044, Санкт-Петербург, ул. Академика Лебедева, д. 2

\footnotetext{
Цель. Определение эффективности и переносимости препарата Сотрет при лечении больных с различными клиническими фрормами и степенью тяжести акне в трех клинических исследованиях.

Материал и методы. Проведено обследование и лечение 103 больных акне (средней и тяжелой степени тяжести, а также конглобатными и инверсными акне). Всем больным был проведен курс монотерапии препаратом Сотрет с оценкой клинической эффективности и регистрацией нежелательных явлений.

Результаты. Проведенная терапия препаратом Сотрет способствовала формированию клинической ремиссии акне в 90-100\% случаев. Нежелательные явления легко переносились и не были серьезными.

Заключение. Доказанная терапевтическая эффективность препарата Сотрет определяет возможность его

применения при различной степени тяжести и различных орормах акне.
}

Ключевые слова: акне средней и тяжелой степени тяжести, конглобатные акне, инверсные акне,

изотретиноин, Сотрет, достижение клинической ремиссии, низкий риск серьезных нежелательных явлений.

Контактная информация: olhovskaya_kira@mail.ru. Вестник дерматологии и венерологии 2015; (5): 128-133. 


\section{Efficiency and tolerance of acne therapy using system isotretinoin}

Yu.N. Perlamutrov', K.B. Olkhovskaya ${ }^{1}$, M.M. Kokhan², Yu.V. Keniksfest ${ }^{2}$, Yu.B. Shaibakova², N.V. Polyakova², E.P. Topychkanova², Ya.V. Kashcheeva², A.V. Samtsov' ${ }^{3}$, A.V. Statsenko², I.E. Belousova ${ }^{3}$, V.R. Khayrutdinov ${ }^{3}$, S.V. Volkova ${ }^{3}$, A.S. Zhukov ${ }^{3}$

${ }^{1}$ State Budgetary Educational Institution "A.I. Evdokimov Moscow State Medical and Denatal University" of the Ministry of Health of Russia

Delegatskaya str., 20, bldg. 1, Moscow, 127473, Russia

${ }^{2}$ Federal State Budgetary Institution "Ural Scientific and Research Institute of Dermatoveneriology and immunopathology" of the Ministry of Health of Russia

Shherbakova str., 8, Ekaterinburg, 620076, Russia

${ }^{3}$ Federal State Budgetary Educational Institution Higher Professional Education "S.M. Kirov Military and Medical Academy"

Academic Lebedev str., 2, St. Petersburg, 194044, Russia

Purpose. Determination of efficiency and tolerance of Sotret product in treatment of patients with different clinical forms and severe acne in three clinical investigations.

Materials and methods. 103 patients with acne (moderate and severe acne, acne conglobata and acne inversa) were examined and treated. All patients underwent monotherapy with Sotret with clinical effectiveness assessment and records of adverse events.

Results. Sotret therapy facilitated clinical remission of acne in $90-100 \%$ of cases. Adverse events were easily tolerated and were not serious.

Conclusion. Established therapeutic efficiency of Sotret determines its potential in treating various severity and various forms of acne.

Key words: moderate and severe acne, acne conglobate, acne inversa, isotretinoin, Sotret, achieving clinical remission, low risk of serious adverse events. 
Акне - одно из наиболее распространенных заболеваний кожи, которое характеризуется мультифракториальным генезом и формированием выраженной психосоциальной дезадаптацией пациентов [1]. По данным различных клинико-эпидемиологических исследований, акне регистрируется у 44,1-94,9\% лиц подросткового возраста и у 18,4-50,9\% лиц старше 21 года. Установлено, что среди подростков с акне преобладают пациенты мужского пола, а среди взрослых - женского [2-4]. В последние годы отмечается также увеличение числа пациентов с акне в возрасте старше 30 лет. При этом до 20\% больных - это пациенты со средней и тяжелой степенью течения заболевания, и примерно у $1 / 4$ пациентов фрормируются остаточные явления в виде рубцовых изменений кожи, псевдоатрофии, гиперпигментированных пятен, дисхромий [5]. Одной из важных эпидемиологических характеристик заболевания является то, что тяжелое течение акне наблюдается у 14-32,5\% больных, среди которых в среднем у 70\% имеется генетическая предрасположенность по линиям обоих родителей, что обусловливает резистентность к большинству методов лечения. В связи с этим ВОЗ определяет акне как хронический и рецидивирующий дерматоз, требующий активного изучения и разработки эфрфективных методов лечения [6, 7].

Основными патогенетическими фракторами развития акне являются гиперпродукция сальных желез и патологическая гиперкератинизация волосяного фолликула, обусловленная воздействием андрогенов, а также микробная гиперколонизация и воспаление [8]. В последние годы использование современных технологий позволило установить роль в активации деятельности сальных желез таких гормонов, как инсулин, гидрокортизон и тироксин. Показано, что синтез свободных жирных кислот может провоцироваться без участия бактериальной биоты. В современных исследованиях уделяется пристальное внимание изучению стимулирующего влияния нейроактивных пептидов (субстанции Р), интерлейкина-1 $\alpha$, антимикробных пептидов на формирование фолликулярного гиперкератоза, комедонов и перифолликулярного воспаления. Считается, что инициация воспалительного процесса при акне осуществляется посредством Toll-подобных рецепторов (TLR - Toll-like receptor), активируемых протеазами рецепторов (PAR-2 - protease-activated receptor-2), рецепторов, активируемых пролифератором пероксисом (PPAR - peroxisome proliferator-activated receptor), что сопровождается миграцией и аккумуляцией лейкоцитов. В свою очередь, остаются плохо изученными патогенетические механизмы развития акне, обусловленные деятельностью Propionibacterium acnes [9, 10].

Повышение эффективности терапии больных акне представляет сложную для решения, крайне актуальную, в том числе и социальную, задачу в связи с по- ражением видимых областей кожи, формированием длительно существующих поствоспалительных проявлений, что часто сопровождается аффективными расстройствами и снижением качества жизни больных $[11,12]$. На современном этапе широкий ассортимент лекарственных средств и доступность медицинской информации позволяют достичь выраженного клинического эффректа в лечении больного акне. Наиболее актуальным вопросом является оказание медицинской помощи пациентам со средним и тяжелым течением заболевания, так как общепринятым считается, что препараты, обладающие наибольшей эффрективностью, обусловливают возникновение ряда нежелательных явлений [13].

Изотретиноин одобрен FDA (Food and Drug Administration) для системной терапии больных акне c 1982 г. В настоящее время препарат остается наиболее эффрективным средством в терапии заболевания, способствуя не только выраженному клиническому результату, но и фрормированию длительной ремиссии и выздоровлению более чем у $80 \%$ больных [14]. В 2012 г. в европейских рекомендациях по лечению больных акне метод монотерапии с использованием изотретиноина отнесен к уровню доказательности 1++ (данные об эфрфективности, полученные из рандомизированных клинических исследований с очень низким риском систематических ошибок или из метаанализов) для лечения больных акне средней и тяжелой степени тяжести, а также особыми формами акне. Эффрективность изотретиноина обусловлена его плеотропным эффректом. Данный препарат не только воздействует на все основные патогенетические механизмы заболевания, снижая продукцию кожного сала и уменьшая размер сальных желез до 90\%, но и способствует устранению иммунного воспаления в перифолликулярной зоне [15].

Приводим результаты трех российских клинических исследований, целью которых являлось определение эффрективности и переносимости системного изотретиноина (Сотрет) при различных фрормах и степени тяжести акне, проведенных на кафедре кожных болезней ГБОУ ВПО “МГМСУ им А.И. Евдокимова» Минздрава России, в ФГБУ «УрНИИДВиИ» Минздрава России и на кафедре кожных и венерических болезней ВМА им. С.М. Кирова МО РФ.

\section{Материал и методы}

В исследованиях приняли участие 103 больных акне (64 женщины и 39 мужчин в возрасте от 15 до 50 лет, средний возраст $24,11 \pm 4,44$ года), в том числе $94-$ со средней и тяжелой степенью заболевания, 6 - с конглобатными акне и 3 - с другими фрормами заболевания (инверсные акне и абсцедирующий подрывающий перифолликулит Гофрфмана).

Всем больным была проведена монотерапия препаратом Сотрет, который был одобрен к применению 
в России с 2011 г. Сотрет выпускается в фрорме капсул, содержащих 10,0 или 20,0 мг изотретиноина в качестве активного вещества, и является единственным дженерическим препаратом в России с доказанной биоэквивалентностью бренду [16].

Суточная доза Сотрета зависела от массы тела пациентов, выраженности побочных реакций и фрормы заболевания. Так, в УрНИИДВиИ был применен метод дифференцированного дозирования препарата: при средней степени тяжести - 0,3-0,4 мг/кг в сутки, при тяжелой - 0,5-0,7 мг/кг в сутки, при кон- глобатных и при других видах акне - 0,75-1,0 мг/кг в сутки. Продолжительность лечения определялась сроками достижения кумулятивной дозы препарата (75-150 мг/кг), а также формой заболевания и составила от 6 до 8 мес. (табл. 1).

Во всех центрах, проводивших исследования, применялась единая методика обследования больных в соответствии с международными согласительными документами по применению изотретиноина у больных акне. Тест определения хорионического гонадотропина в крови проводился женщинам с сохранен-

\section{Таблица 1 Общие характеристики пациентов и методика проводимой терапии}

\begin{tabular}{|c|c|c|c|}
\hline Характеристика & $\begin{array}{c}\text { МГМСУ } \\
\text { им А. И. Евдокимова }\end{array}$ & УрНИИДВиИ & $\begin{array}{c}\text { ВМА } \\
\text { им С.М. Кирова }\end{array}$ \\
\hline Возраст, годы & $22,14 \pm 4,09$ & $26,18 \pm 5,07$ & $24 \pm 4,16$ \\
\hline Общее число больных & 30 & 23 & 50 \\
\hline $\begin{array}{l}\text { В том числе, абс. (\%): } \\
\text { с акне средней степени тяжести }\end{array}$ & $19(63,33)$ & $10(43,48)$ & 0 \\
\hline с акне тяжелой степени тяжести & $11(36,67)$ & $8(34,78)$ & $47(94,00)$ \\
\hline с конглобатными акне & 0 & $2(8,70)$ & $3(6)$ \\
\hline с другими формами акне & 0 & $3(13,04)$ & 0 \\
\hline Терапия & Сотрет & Сотрет & Сотрет \\
\hline Суточная доза, мг/кг & $0,5-1,0$ & $0,3-1,0$ & $0,4-0,8$ \\
\hline Курсовая доза, мг/кг & $120-150$ & $75-130$ & 120 \\
\hline
\end{tabular}

\section{Таблица 2 Результаты лечения больных акне с использованием препарата Сотрет по данным разных центров}

\begin{tabular}{|c|c|c|c|}
\hline \multirow{2}{*}{ Группа обследованных } & $\begin{array}{c}\text { МГМСУ } \\
\text { им А.И. Евдокимова }\end{array}$ & УрНИИДВиИ & $\begin{array}{c}\text { ВМА } \\
\text { им С.М. Кирова }\end{array}$ \\
\hline & ДИА & ОТУ & ДИА \\
\hline \multicolumn{4}{|c|}{$\begin{array}{l}\text { Больные акне средней степени } \\
\text { тяжести: }\end{array}$} \\
\hline до лечения & $8,56 \pm 1,05$ & $11,3 \pm 2,1$ & - \\
\hline после лечения & 0 & $1,0 \pm 0,2$ & - \\
\hline \multicolumn{4}{|c|}{$\begin{array}{l}\text { Больные акне тяжелой степени } \\
\text { тяжести: }\end{array}$} \\
\hline до лечения & $12,15 \pm 1,68$ & $14,5 \pm 2,6$ & $12,2 \pm 1,4$ \\
\hline после лечения & $1,15 \pm 0,02$ & $3,5 \pm 0,9$ & $1,6 \pm 0,3$ \\
\hline \multicolumn{4}{|c|}{ Больные конглобатными акне: } \\
\hline до лечения & - & $17,5 \pm 0,5$ & $13,4 \pm 1,7$ \\
\hline после лечения & - & $6,3 \pm 1,1$ & $1,8 \pm 0,9$ \\
\hline \multicolumn{4}{|c|}{$\begin{array}{l}\text { Больные с другими формами } \\
\text { акне: }\end{array}$} \\
\hline до лечения & - & ОТУ не определялся & - \\
\hline после лечения & - & ОТУ не определялся & - \\
\hline
\end{tabular}


ной репродуктивной функцией ежемесячно и через 30 дней после окончания терапии, клинический анализ крови - на этапе скрининга, исследование липидограммы - до лечения, через месяц и в конце терапии, определение активности фрерментов печени в крови до лечения, через месяц, далее 1 раз в 3 мес. и после окончания терапии $[17,18]$.

Оценка тяжести течения акне проводилась на основании динамики дерматологического индекса акне ДИА (МГМСУ им А.И. Евдокимова и ВМА им. С. М. Кирова) и по сумме баллов патологических элементов общая тяжесть угрей - ОТУ (УрНИИДВиИ).

\section{Результаты исследований}

Во всех исследовательских центрах в среднем были получены сопоставимые результаты лечения больных (табл. 2).

У всех больных была зарегистрирована выраженная и достоверная динамика дерматологических тестов, отражающих тяжесть течения акне. Важным показателем эфффективности терапии акне является частота случаев формирования клинической ремиссии, которая после лечения больных с заболеванием средней или тяжелой степени тяжести препаратом Сотрет составила 90\% в УрНИИДВиИ, 93,33\% в МГМСУ им. А.И. Евдокимова и 100\% в ВМА им. С.М. Кирова. При лечении больных с особыми фрормами дерматоза использование Сотрета привело к выраженному клиническому улучшению (снижение интенсивности клинических симптомов акне более чем на $75 \%$ ).

При наблюдении за больными были получены различные результаты по частоте нежелательных явлений (НЯ), за исключением НЯ, свойственных всем больным, принимающим данный препарат: в 91,3$100 \%$ случаев был зарегистрирован хейлит и более чем у $60 \%$ пациентов - ретиноевый дерматит. Реже отмечались другие НЯ: сухость слизистых, носовые кровотечения, диспепсия и головная боль. Важно отметить, что у всех больных НЯ не являлись серьезными, не требовали прекращения проводимой терапии и легко переносились. Изменения в биохимическом анализе крови были зарегистрированы у 12 (11,65\%) больных и носили транзиторный характер.

\section{Заключение}

Анализ результатов трех российских клинических исследований по определению эффективности и переносимости препарата Сотрет продемонстрировал высокую терапевтическую эффективность и низкий риск формирования серьезных НЯ, что обусловливает целесообразность его активного применения с целью повышения качества оказания медицинской помощи больным акне. I

\section{Литература}

1. Zouboulis C.C., Katsambas A.D., Kligman A.M. Pathogenesis and treatment of acne and rosacea. Springer Heidelberg New York Dordrecht London 2014, 53.

2. Cordain L., Linderberg S., Hurtado M. et al. Acne vulgaris: a desease of Western civilization. Arch Dermatol 2002; 119: 1317-1322.

3. Shalita A.R. Acne: clinical presentations. Clin Dermatol 2004; 22: 385-386.

4. Dreno B., Poli F. Epidemiology of acne. 20-th World Congress Dermatology. Ann Dermatol Venerol 2002; 132.

5. Kungurov N.V., Kokhan M.M., Zil'berberg N.V. i dr. Terapiya bol'nykh akne i postakne. Metodicheskie rekomendatsii. Ekaterinburg, 2013; 6. [Кунгуров Н.В., Кохан М.М., Зильберберг Н.В. и др. Терапия больных акне и постакне. Методические рекомендации. Екатеринбург, 2013; 6.]

6. Lee M.R. Cooper A. Acne vulgaris in monozygotic twins. Australas J Dermatol 2006; 47: 145.

7. Thiboutot D., Gollnick H., Bettoli V. et al. New insights into the management of acne: an update from the Global Alliance to Improve Outcomes in Acne group. J Am Acad Dermatol 2009; 60: 1—50.

8. Zouboulis C.C. Acne as a chronic systemic disease. Clin Dermatol 2014; 32: 389—396.
9. Statsenko A.V., Belousova I.E., Khayrutdinov V.R. et al. Clinical experience of administering isotretinoin in therapy of severe acne. Effective Pharmacotherapy 2014; (4): 3-5. [Стаценко A.В., Белоусова И.Э., Хайрутдинов В.Р. и др. Клинический опыт применения изотретиноина в терапии тяжелых форм акне. Эффективная фармакотерапия 2014; (4): 3-5.]

10. Gollnick H. Current concept of the pathogenesis of acne: implication for drug treatment. Drugs 2003; 63: 1579_1596.

11. Samgin M.A, Monakhov S.A. Sovremennyy vzglyad na vospalenie pri akne. Vestn dermatol venerol 2003; (6): 48-49. [Самгин M.A., Мoнахов С.А. Современный взгляд на воспаление при акне. Вестн дерматол венерол 2003; (6): 48-49.]

12. Cunliffe W.J. Acne: when, where and how to treat. Practitioner 2000;. 244; 865—866, 868, 870-871.

13. Perlamutrov Yu.N., Ol'khovskaya K.B. Sovremennye aspekty effektivnoy terapii acne vulgaris. Russ J Skin Venereal Dis 2014; (5): 51-54. [Перламутров Ю.Н., Ольховская К.Б. Современные аспекты эффективной терапии асnе vulgaris. Росс журн кожн вен бол 2014; (5): 51-54.]
14. Wolverton S.E., Harper J.C. Important controversies associated with isotretinoin therapy for acne. Am J Clin Dermatol 2013; 14: 71—76.

15. Nast A., Dréno B., Bettoli V. et al. European evidence-based (S3) guidelines for the treatment of acne. J Eur Acad Dermatol Venereol 2012; 1 : $1-29$.

16. Kokhan M.M., Keniksfest lu.V., Shaübakova lu.B. et al. Experience of treating patients with various forms of acne using systemic isotretinoin. Clin Dermatol Venerol 2014; (2): 91—99. [Koхан М.М., Кениксфрест Ю.В., Шайбакова Ю.Б. и др. Опыт терапии больных различными формами акне препаратом системного изотретиноина. Клин дерматол венерол 2014 (2); 91-99.]

17. Layton A.M., Dreno B., Gollnick H.P. et al. A review of the European Directive for prescribing systemic isotretinoin for acne vulgaris. J Eur Acad Dermatol Venereol 2006; 20: 773 - 776 .

18. Goodfield M.J., Cox N.H., Bowser A. et al. Advice on the safe introduction and continued use of isotretinoin in acne in the U.K. 2010. Br J Dermatol 2010; 162: 1172—1179. 
об авторах:

Ю.Н. Перламутров — заслуженный врач РФ, д.м.н., профессор, зав. каффедрой кожных и венерических болезней ГБОУ ВПо МГМСУ им А.И. Евдокимова Минздрава России, Москва

К.Б. Ольховская — к.м.н., доцент кафедры кожных и венерических болезней ГБОУ ВПо МГМСУ им. А.И. Евдокимова Минздрава России, Москва

М.М. Кохан - д.м.н., профрессор, зав. научным клиническим отделом дерматологии ФГБУ «Уральский научноисследовательский институт дерматовенерологии и иммунопатологии» Минздрава России, Екатеринбург

Ю.В. Кениксфрест — д.м.н., доцент, ведущий научный сотрудник научного клинического отдела дерматологии

ФГБУ «Уральский научно-исследовательский институт дерматовенерологии и иммунопатологии» Минздрава России, Екатеринбург

Ю.Б. Шайбакова — врач-дерматовенеролог ФГБУ «Уральский научно-исследовательский институт дерматовенерологии и иммунопатологии» Минздрава России, Екатеринбург

Н.В. Полякова — младший научный сотрудник научного клинического отдела сифилидологии и ИППП ФГБУ «Уральский научно-исследовательский институт дерматовенерологии и иммунопатологии» Минздрава России, Екатеринбург

Е.П. Топычканова - к.М.Н., научный сотрудник научного клинического отдела дерматологии ФГБУ «Уральский научноисследовательский институт дерматовенерологии и иммунопатологии» Минздрава России, Екатеринбург

Я.В. Кащеева — к.М.Н., научный сотрудник научного клинического отдела дерматологии ФГБУ «Уральский научноисследовательский институт дерматовенерологии и иммунопатологии» Минздрава России, Екатеринбург

А.В. Самцов - д.м.н., профессор, зав. кафредрой кожных и венерических болезней ФГБВОУ ВПО «Военно-медицинская академия им. С.М. Кирова» МО РФ, Санкт-Петербург

А.В. Стаценко - Д.м.Н., зам. зав. кафедрой кожных и венерических болезней ФГБВОУ ВПО «Военно-медицинская академия им. С.М. Кирова» МО РФ, Санкт-Петербург

И.Э. Белоусова - д.м.н., доцент, профессор кафедры кожных и венерических болезней ФГБВОУ ВПО «Военно-медицинская академия им. С.М. Кирова» МО РФ, Санкт-Петербург

В.Р. Хайрутдинов — д.м.н., ассистент кафедры кожных и венерических болезней ФГБВОУ ВПО «Военно-медицинская академия им. С.М. Кирова» МО РФ, Санкт-Петербург

С.В. Волкова — ассистент кафедры кожных и венерических болезней ФГБВОУ ВПО «Военно-медицинская академия им. С.М. Кирова» МО РФ, Санкт-Петербург

А.С. Жуков — к.м.н, адъюнкт кафредры кожных и венерических болезней ФГБВОУ ВПО «Военно-медицинская академия им. С.М. Кирова» МО РФ, Санкт-Петербург

\section{Конфликт интересов}

Авторы заявляют об отсутствии потенциального консрликта интересов, требующего раскрытия в данной статье 